\title{
Working but Poor: Perspectives from a Rural, African American Family
}

\author{
Pearl Stewart
}

\begin{abstract}
This case study utilized qualitative methodology to examine the lived experience of a rural, extended, African American family as they coped with the challenges of working but remaining poor. The strategies utilized to 'work for a living' in a rural environment which had limited job opportunity and limited infrastructural support were explored. The data suggests that the support and intervention of this extended family system was crucial to the success of the participants.
\end{abstract}

Pearl E. Stewart, Ph.D. is Assistant Professor, Department of Family and Child Studies, Montclair State University, Montclair, NJ, 07043. Electronic mail may be sent via the Internet tostewartp@mail.montclair.edu.

Key words: Working Poor, Rural, African American, Qualitative Research

\section{Introduction}

While much attention has been focused on moving families beyond welfare, little attention has been given to the destination of many of those families. Research indicates that far from achieving self sufficiency, many join the ranks of the working poor. This group has been an omnipresent but invisible part of the American workforce. This lack of visibility has been based on the assumption that working poverty was a temporary situation (Shulman, 2004) which will be rectified as the worker gains in 
experience and seniority. For many workers this was not the case, since a variety of structural and individual factors prevent such advancement. This was particularly true with respect to rural areas where infrastructural and employment issues can thwart all but the most thoughtful intervention attempts.

Who are the Working Poor?

While various definitions have been used to classify the working poor, their numbers, by any definition are surprising. In $2003,20 \%$ of the nation's poor were individuals who worked for at least 27 weeks of the year. And, of that number, three in every five worked full time (U.S. Department of Labor, 2005). One third of children born to working families are part of low income families (Kahne, 2004). Those numbered among the working poor span all races/ethnicities but those of African or Latino descent are more than twice as likely as Whites to be among the working poor (U.S. Department of Labor, 2005). Shulman (2004) offers an excellent description of this population:

They are all around us in jobs essential to our lives. Low wage workers are security guards and childcare givers. They are nursing home workers and retail clerks. They are hospital orderlies and teacher's assistants. They are hotel workers and pharmacy technicians. They bone the chicken that we eat, clean the office buildings where we work and handle our questions and complaints at call centers. (p. 21)

While some of these employment options require education or training beyond high school, that training does not always translate into higher wages (Blalock, Tiller, \& Monroe, 2004).

Why Does the Working Poor Population Continue to Grow?

The number of Americans who comprise the working poor has risen over the past decade and continues to grow (Kim, 1998). A variety of reasons have been advanced to explain this increase. Changes in employment structure, including the loss of high wage 
manufacturing jobs has limited the opportunities available for those without advanced degrees (Gringeri, 2001). The restructuring of the welfare system was among the most important factors in the rise of the working poor population. This restructuring has forced former and current welfare recipients, with limited education and training into the low wage job market where jobs provide few, if any, benefits, and little if any opportunity for advancement (Whitener, Gibbs, \& Kusmin, 2003). While the stated intent of this strategy was to get people into the work force so that they could "work their way up", that scenario rarely occurs due to structural factors beyond the control of the worker (Whitener et al., 2003). The failure of the minimum wage to keep pace with the cost of living has made salaries earned in low wage jobs less valuable in the marketplace (Kahne, 2000; Spriggs, 2006).

Low wages are among the chief reasons that workers remain among the working poor and this was never truer than among residents of rural areas (Kahne, 2004; Kim, 1998). For those living in rural areas, wages are often significantly lower than wages received in more urban areas (Gringeri, 2001). Kahne's (2004) work on low-wage, single mothers reveals that those working for $\$ 6$ per hour, which is above the federal minimum wage, could not earn a salary above the poverty level for a family of two. Yet these low wage workers "make up the core of much of the new economy. And it was estimated that low wage jobs will make up $30 \%$ of the economy by the end of the decade" (Shulman, 2004, p. 21). Such jobs currently provide the bulk of employment opportunities in rural areas (Whitener et al., 2003).

\section{Challenges to Health}

Lack of access to health care represents a significant challenge for those who are working but poor. Low income families are significantly less likely to have employer financed health insurance than are middle or high income families (Shulman, 2004). The lack of ability to pay often results in the 
postponement of treatment of minor ailments which may lead to permanent damage or serious acute care or to the failure to address serious chronic conditions such as diabetes and hypertension (Blalock et al., 2004). Ultimately untreated health issues can lead to missed days of work, a lowering of earnings or the loss of employment. When acute or serious conditions force the uninsured worker to seek medical care, the significant debts incurred further strain, the budgets and resources of the working poor (Gringeri, 2001)

While the inability to pay was often issue cited when discussing healthcare related issues for low wage workers, the rural working poor might be equally affected by the lack of healthcare infrastructure. For this population the inability to access health care may be caused by a lack of medical facilities or medical staff as well as by an inability to pay. Research indicates that the distribution of medical facilities and medical staff was skewed toward urban areas, leaving rural residents without accessible care (Ricketts, 2000).

\section{Family Supports}

For members of working poor families, the help of kin can be part of a "complex web," (Blalock et al., 2004), that has costs and benefits. Research indicates that those who escape the cycle of poverty do so through a combination of hard work, formal and informal support (Gray, 2005). Edin and Lein (1997) speak of the importance of support systems and resource sharing in the lives of low wage earners. African American families have a history of resource sharing that is part cultural ethos and part economic necessity. This sharing of instrumental, social, and emotional resources has been important to the identity, survival, and/or advancement of African Americans but these benefits come with an understanding of reciprocity. There is an unspoken expectation that resources are to be pooled and available for the use of all. This may result in a process referred to as leveling. In this process, "resources must be available to all and none may get ahead (Rapp, 
1992, p. 61)." If one accumulates resources beyond one's needs, the expectation that the individual will share those resources with the remainder of the network was implicit. The expectation of financial and emotional support when needed and the expectation of sponsorship are held even if the giving of that support interferes with the advancement of the giver (Stack, 1974). This sponsorship make take the form of providing short or long term, rent free housing, other forms of kin keeping or ongoing financial support.

This case study examined the experiences of rural, extended, African American family members as they coped with the challenges of working but remaining poor. This study sought to illuminate the unique problems faced by the rural working poor as well as the strategies utilized to address those problems.

\section{Methods}

\section{Participants}

The participants in this study were part of a single, African American, extended family with its roots and most of its members living in a rural community in the Southeastern United States. Information from interviews conducted with 14 adult extended family members and four community informants provided data for this study. This subgroup of interviews is part of a larger data set of 45 interviews with members of this family group. Individuals were considered to be among the working poor if they had worked full time but still met the criteria for lower-class status based upon the Hollingshead-Relich Two Factor Scale (Stanley \& Hopkins, 1972). The age range of the participants was 30-74 years.

\section{Procedure}

Data were gathered between July 2001 and February 2002 using both semistructured interviewing and participant observation. These methods were chosen because they can each be used in an informal and nonintrusive manner and were consistent 
with African American cultural and behavioral traditions. MacAdoo (1991) described African Americans as an oral people, and use of semistructured interviews allowed participants to pass on information in a way that was comfortable for them and that was in keeping with their traditional mode of information sharing.

To facilitate the participant observation portion of data collection, the researcher relocated to the community and became part of the daily lives of the participants. Attendance at community, family, school, and church events was essential in understanding the lived experience of these participants (Fetterman, 1998). This participation provided ample opportunity to observe the members of the group in pursuit of their daily activities and thus to observe if their ordinary actions and verbalizations were consistent with the information provided during interviews. Interviews were audio taped with the permission of the participants later transcribed verbatim.

\section{Data Analysis}

The data for this study were generated from the verbatim transcriptions of the individual interviews and from the field notes of the researcher. A grounded theory approach was used in the analysis of this data (Glaser \& Strauss, 1967; Strauss \& Corbin, 1998). The initial step in this process was open coding. During open coding each line or segment of data was assigned a label/code. These labels/codes provided a framework to begin developing themes. The next step in the coding process was axial coding. The next step in the coding process was axial coding. In axial coding, those themes identified initially were examined more closely to produce categories and subcategories. During the process of axial coding, two major themes were identified. Selective coding was used to identify specific quotations that illustrated the major themes in the data.

At several points during the analysis, the researcher presented her interpretations and analysis to various study participants and to community informants in order to determine if 
there were areas of misunderstanding or misinterpretation. This practice, known as member checking, ultimately strengthens the "trustworthiness" of the researcher's interpretation of the meanings of the data (Lincoln \& Guba, 1985).

\section{Results and Discussion}

Three areas of interest emerged during the course of analysis: Finding Work; Challenges to Health Care; and Utilizing Family Resources.

\section{Finding Work}

For the participants in this study, there was a clear recognition that work was essential and "right." All but the retirees were involved in some type of paid employment although many had been forced into the informal labor market due to factory closings, health issues, and/or infrastructural issues. The concerns most salient for this group were job availability and the need to work multiple jobs in order to survive.

\section{Job availability}

As is the case in many rural communities, there was a general lack of jobs or a lack of jobs which paid a livable wage (Blalock et al., 2004). Harry clearly made this point:

Just ain't no jobs around here now. Back then you could get a job everyday, no problem. Now there ain't no jobs. And if you git a job, it don't pay hardly nothing.

For Harry, "back then" refers to the time when there were factories where those of limited education could be trained and work. Many of these factories were closed or had been automated to a degree that made human labor unnecessary or unprofitable. In addition, work with the crops (cotton, tobacco, peanuts) that once were the 
employment "fallback" position for African Americans in the region had disappeared. The advent of farm machinery and increasingly more efficient farming techniques rendered the farm workers redundant and unemployed. For example, "in 1950 practically all southern cotton was picked by hand; by the end of the 1960 s over $90 \%$ was picked by machine (Winters, 1998, p. 12)." The lack of available farm work was especially important for African Americans because they were without the skills or education to do other work. Roland, one of the elders interviewed for the study spoke to these issues:

When the fields had to be picked by hand, it gave a lot of people a chance to work and have jobs. You got machines to do all the heavy work the people used to have to do. You got machines now some of that was good but that throwed a lot of people out of a job. That was a ways back. Same thing happened agin when they got machines in the factories.

Linda, a social services worker and community informant, provided support for those assertions:

Around here, it's a lack of jobs, number one. And number two, lack of a livable wage for most of the jobs that you can get without a Bachelor's, especially for Black folks. Those jobs just not gonna pay enough to take care of a household. My son was working at Perdue right now and he's single, no kids. He's bringing home 'bout 201, 209 a week. My aunt just retired from the same place and she bring home a little bit more. And he hasn't been working 6 months yet. So I know it would be hard to take care of a family on $\$ 200$ a week. And a lack of education. 'Cause the way it was now, if you don't have a high school diploma you can't get a job anywhere outside of fast food.

Factories, the ones that ain't closed down, won't even hire you. Most factories nowwon't hire you without a GED or a Diploma. That just leaves fast food or Walmart. 
The changing economy and technological advances left these participants with few employment options.

\section{Multiple jobs}

One of the strategies employed with respect to making work suffice was the maintenance of multiple jobs. The work of Gringeri (2001) discussed the use of multiple jobs as a strategy to meet the economic needs of a family. Emily, who worked full time yet remained in poverty, provided the most extreme example of one who followed "the rules" but who has been unable to move beyond working-poor status. Emily was a 38-year-old, married mother of 2 sons. Her sons were ages 13 and 2 at the time the data was collected. Her husband was employed at the beginning of the study but lost his job soon after the beginning of data collection so did not represent an economic asset for the family. Emily had two full time jobs (35 hour each). Both jobs paid slightly above the minimum wage for her state. Emily's combined annual income was approximately $\$ 25,000$, and neither job provided health benefits. Emily was certified as a nurses' aide and as a lab technician. Both credentials were obtained from the local community college. For Emily, all efforts-including attendance at community college to gain the certifications required for her jobs-did not prove sufficient to move her beyond the ranks of the working poor because certification had no impact on either wage structure or job availability. The work of Blalock and her associates (2004) supports the finding that the connection between increased human capital and advancement may not hold for those living in rural areas.

Emily was not alone among her family members with respect the historical need to work need to work multiple jobs to garner a survival level income. For Harry, the issue of wages led him to a combination of formal and informal sources of income: 
I was a cheffor 16 years-basically at the T. Restaurant. It closed, then it was BC's. I cooked there 5 years. Never really made no money though. Not enough to really get by. I had my barbering. It's not something I want to do steady. It's more like a

sidekick for me. Brings in that extra money you need to get by.

The sideline barbering of which Harry spoke was, in fact, more steady than he perceived it to be. Observation by the researcher over a period of months revealed that he had a steady and consistent clientele. Most Saturdays mornings his home had a stream of men coming for haircuts. Many of those present were men related by blood or marriage, others held fictive kin status, and still other men were unrelated but in need of a barber with a good reputation. Those sessions also served social and networking opportunities for men in need of companionship and job tips.

The job tips were rarely of the type which could provide full-time, year-round work but were generally news of who needed "a few guys to clean out a barn" or someone who was hiring seasonal workers. Many of these participants relied on "pick up work" and day labor to meet their economic needs. The use of seasonal or temporary work was a well documented method of piecing together a living among the working poor (Gringeri, 2001).

\section{Health Care and Low Wage Work}

Among the participants in this study was evidence of both the immediate and long-term effects of the lack of health-care access. Emily, whose two full-time jobs are in the health profession, was in the somewhat ironic position of having no health benefits for herself or her children. What was even more ironic was that her position as a home health aide was funded almost entirely by the health insurance benefits of the people she serves. When describing her concern about health care she said: 
I do what I can to keep everyone healthy, but with boys you just never know. Mostly I just pray that nobody gets sick or hurt. We just can't afford it, especially if it's me. If I get sick, we're in trouble. Not just me and the kids but all the people I help out.

Also expressing concern for the lack of health care was Cynthia, who when asked about her caregiving duties spoke primarily of issues related to the elders in the family and their lack of health benefits:

And the older people. We try to look out for them but lots of the time they just can't afford what they need, as far as medicine goes. Or even going to the doctor. Sometimes they won't even tell you when they feel bad. It's sad. They done worked all their lives, in the fields, or factories, or cleaning other people's houses. Now they old and can't buy medicine. It's not right. And I wonder what it will be like when I get real old. I lost my job when the factory closed down but soon as I find something I'll be back at work but I ain't got no insurance neither, never had none. I'm lucky I didn't have to spend no time in the field. Maybe that's what made them sick like this, all that worrying way back then.

Cynthia's thoughts were clearly on elders such as Roland, who spent his entire life among the working poor. For him, there was virtually no safety net to support him as he entered his $75^{\text {th }}$ year. He had never had health insurance or regular health care and now the consequences of a life of hard, physical labor and stress were becoming apparent. He suffered from a collection of chronic illnesses that required numerous medications. His meager social security benefits often did not allow him to purchase medication or to take them as prescribed. Field notes collected during this study describe one example of the hard choices those such as Roland must make: 
Today I was asked to drive Roland to the drugstore. He had finally been to the Emergency Room after being in bed for 4 days. The doctor prescribed a new heart medication, something for high blood pressure and an antibiotic for the current respiratory infection. At the pharmacy, Roland 'priced' each of the medications. He decided to invest in the heart medication. He had determined that this was the most 'important medicine' though the respiratory infection that had kept him in bed was the most immediately problematic. He asked for 25 dollars worth and was given 6 pills. The prescription called for the medication to be taken twice a day. He indicated that he would try to get more when he got his check. (Field notes, November, 2001)

Emily and Cynthia each experienced the stress of inadequate healthcare for their children, their parents and, lastly, themselves. The elders either suffer in silence or wonder how different their lives could have been if medical care had been available.

\section{Utilizing Family Resources to Cope}

The shared resources of a support group, in this case an extended family including fictive kin, are essential components for survival or success for the working poor (Edin \& Lein, 1997). The ability to access those resources and the willingness to be a resource to others can be the difference between keeping and losing a job, being able to pay bills, or having housing. These participants identified support with caregiving tasks and housing as chief among the resources needed by those who work but remain poor. 


\section{Caregiving}

The utilization of members of the family social support system was essential to the survival of many of the participants. These informal support systems were accessed to provide child care for those family members who were able to find steady, full time, or occasional work. The use of kin to provide childcare and other caregiving duties was well documented in the literature on African American families (Gammon, 2000; Hunter, 1997) and in the research on families living in poverty (Edin \& Lein, 1997; Gringeri, 2001). Also documented in the literature was the importance of reliable child care for those committed to work or education as a means to rise beyond poverty.

These arrangements were sometimes complex and multifaceted. For example, since Emily worked 16 hours a day, she was faced with the need to find all-day and night-time care for her two-year-old son, afterschool supervision for her 13-year-old son, and someone to "keep a watchful eye" on her ailing parents. For this purpose she enlisted the aid of Geraldine, a women holding fictive kin status in the family. Geraldine described the arrangement in this way:

I look after Emily's baby boy. I go over to they house (the grandparents). But I don't call that no work. I just look after the baby. See my place here was so small and I can't keep no little children here. He might run into the tableanything and hurt himself and I don't want to see no scars on him. I just stay all day and if Emily's parents need something, they both ailing, I'm right there, you know.

Other communication with relatives and observations documented in the field notes indicate that Geraldine's presence in the household also served to keep Emily informed about potential health issues for her parents. For these services, Geraldine was paid a token sum. This sum helped Geraldine to stretch her

disability payments. Geraldine's disability stems from a 
workplace injury that was left untreated due to alack of health benefits.

\section{Housing}

For many who exist among the working poor, finding adequate housing presents a significant challenge. Housing proved to be a significant area of concern for the members of this study. While none in this group were homeless, owing to the family tradition of taking in kin, many of those working full time were unable to afford "their own place." About 50\% of the full-time workers were "staying with" a family member, and $75 \%$ had done so during their adult working lives. These numbers included those with or without children. Emily lived in a mobile home which rests on a small piece of land behind the home of her parents. Without this support, Emily would have no chance of owning a home nor would her annual salary stretch to the payment of rent.

Matthew, one of the community informants, reported taking in an adult relative who needed a "new start":

What's going on-trying to give other people a hand up, if they're really trying wasn't unusual at all. You have to. If you been helped or realize you might need help someday. One of my cousins, in fact he lived with me a couple years. My father's sister's son. The oldest of those 8 kids. We used to live beside each other. Yeah we all grew up together. He came to stay with me. He stayed with me a couple years. In fact he just left in May. He wasn't really doing very well physically. He was one of those guys who really tried hard but could just never get it together. He needed a chance. So I had been trying to get him to stay with me 'cause he needed a change. I said stay a while, don't worry about no rent get yourself a job. Get yourself together. And he did just that. He needed some support and I gave it to him, the way people gave help to me. 
This sharing of housing space was a necessary strategy for those in need but was also part of the reciprocal obligation of those who had space and or had received assistance in the past.

\section{Conclusions and Recommendations}

Efforts to address issues related to poverty have increasingly come to focus on the importance of workforce participation. While it was true that participation in the workforce was central to the alleviation of poverty, the existence of a significant number of individuals who work full time and remain in poverty gives one reason to doubt that current policies and interventions address the needs of the working poor. There is a need to broaden perspectives and to develop more comprehensive and thoughtful interventions to address poverty in general and the needs of those who are working but poor.

As is the case with all efforts to address poverty, the solutions are complex. An initial step is further research into the needs of rural residents and the ways to reach those residents. Reaching rural residents will require an investment in the form of outreach activities. For example, how will potential clients be made aware of available services? In urban areas, one often sees announcements about new programs and services on the sides of buses or other forms of public transportation. Given the dearth of public transportation in rural areas, other strategies may need to be adopted. An agency might team with local churches or cooperative extension agents to make citizens aware of services. For many of the elders in this community, there are programs which could help them to access medical care and to get assistance in the purchase of medicine, yet the elders and their children seemed unaware of these resources. The researcher noted some notices in places such as the public library but those of limited education are not likely to frequent such places.

Local job creation would also appear to be a logical step to addressing in addressing the issues of the working poor. However, this strategy must be tempered by several caveats. The jobs 
created must offer a livable wage and must be jobs which are available to the local population. Companies are often lured to rural areas using tax incentives and promise to bring high paying jobs with them. Such was the case in the community which hosted this study. In the end, few local residents were qualified for the jobs offered by the company. The company brought many of its own employees and the community was forced to make up the losses in state and local tax revenue from its own residents. This actually resulted in a loss of services for the residents rather than the gains that had been promised.

Finally, additional scholarly work should be done regarding the lives of rural residents. The body of research on rural populations is sparse. This lack of depth leads to the propagation of stereotypes and to the belief that rural populations are not faced with serious social and service issues.

\section{References}

Blalock, L. L., Tiller, V. R., \& Monroe, P. A. (2004). They get you out of courage: Persistent deep poverty among former welfare-reliant women. Family Relations, 53, 127-137.

Edin, K., \& Lein, L. (1997). Making ends meet: How single mothers survive welfare and low wage work. New York: Russell Sage Foundation.

Fetterman, D. M. (1998). Ethnography. In L. Bickman \& D. J. Rog (Eds.), Handbook of applied social research methods (pp. 473-505.) Thousand Oaks, CA: Sage.

Gammon, E. A. (2000). Examining the needs of culturally diverse, rural caregivers who have adults with severe developmental delays living with them. Families in Society: The Journal of Contemporary Human Services, 81, 174-184. 
Glaser, B.G., \& Strauss, A. L. (1967). The discovery of grounded theory: Strategies for qualitative research. New York: Aldine de Gruyter.

Gray, K. A. (2005). Women who succeeded in leaving public assistance for a living wage job. Qualitative Social Work, 4, 309-326.

Gringeri, C. (2001). The poverty of hard work: Multiple jobs and low wages in family economies of rural Utah households. Journal of Sociology \& Social Welfare, 28, 3-22.

Hunter, A. G. (1997). Counting on grandmothers: Black mother's and fathers' reliance on grandmothers for parenting support. Journal of Family Issues, 18, 251-270.

Kahne, H.(2004). Low wage, single-mother families in the jobless recovery: Can improved social policies help? Analyses of Social Issues \& Public Policy, 4, 47-68.

Kim. M. (1998). Are the working poor lazy? Challenge, 41(3), 85-99.

Lincoln, Y. S., \& Guba, E. G. (1985). Naturalistic inquiry. Beverly Hills, CA: Sage.

MacAdoo, H. P. (1991). Family values and outcomes for children. Journal of Negro Education 60(3), 361-365.

Rapp, R. (1992). Family and class in contemporary America: Notes toward an understanding of Ideology. In B. Thorne \& M. Yalom (Eds.), Rethinking the family: Some feminist questions (pp.49-70). Boston: Northeastern University Press.

Ricketts, T. C. (2000). The changing nature of rural health care. Annual Review of Public Health, 21, 639-657. 
Shulman, B. (2004). Working and poor in the USA. Nation, $278(5), 20-22$.

Spriggs, W. E. (2006). Poverty in America: The poor are getting poorer. Crisis, (January/February), 14-18.

Stack, C. B. (1974). All our kin. New York: Harper and Row.

Stanley, J. C., \& Hopkins, K. D. (1972). Educational and psychological measurement and evaluation. Englewood Cliffs, NJ: Prentice Hall.

Strauss, A., \& Corbin, J. (1998). Basics of qualitative research $\left(2^{\text {nd }} e d\right)$. Newbury Park, CA: Sage.

U.S. Department of Labor. (2005). Report 983. A profile of the working poor 2003. Washington, DC: Bureau of Labor Statistics.

Whitener, L. A., Gibbs, R., \& Kusmin, L. (2003). Rural welfare reform: Lessons learned. Amber Waves, 1(3), 38-44.

Winters, D. L. (1998). Agriculture in the post World War II South. In R. D. Hurt (Ed.), The rural South since World War II (pp. 8-27). Baton Rouge, LA: Louisiana State University Press. 